
\title{
28 Research Square \\ Effects of Positioning Conditions on Material Properties In Powder bed Fusion Additive Manufacturing
}

Mevlüt Yunus Kayacan ( $\sim$ mevlutkayacan@isparta.edu.tr)

Isparta Applied Science University https://orcid.org/0000-0003-3557-9537

Nihat Yılmaz

Isparta Applied Science University

\section{Research Article}

Keywords: Additive manufacturing, selective laser melting, Ti6Al4V, thermal effect, temperature distribution

Posted Date: March 31st, 2021

DOI: https://doi.org/10.21203/rs.3.rs-369807/v1

License: (c) (i) This work is licensed under a Creative Commons Attribution 4.0 International License. Read Full License 


\section{Abstract}

Among additive manufacturing technologies, Laser Powder Bed Fusion (L-PBF) is considered the most widespread layer-by-layer process. Although the L-PBF, which is also called as SLM method, has many advantages, several challenging problems must be overcome, including part positioning issues. In this study, the effect of part positioning on the microstructure of the part in the L-PBF method was investigated. Five Ti6Al4V samples were printed in different positions on the building platform and investigated with the aid of temperature, porosity, microstructure and hardness evaluations. In this study, martensitic needles were detected within the microstructure of Ti6Al4V samples. Furthermore, some twins were noticed on primary martensitic lines and the agglomeration of $\beta$ precipitates was observed in vanadium rich areas. The positioning conditions of samples were revealed to have a strong effect on temperature gradients and on the average size of martensitic lines. Besides, different hardness values were attained depending on sample positioning conditions. As a major result, cooling rates were found related to positions of samples and the location of point on the samples. Higher cooling rates and repetitive cooling cycles resulted in microstructures becoming finer and harder.

\section{Introduction}

Additive manufacturing (AM) processes are considered game-changer in the industrial field due to their ability to produce complex geometries without waste of feedstock material [1]. In particular, Powder Bed Fusion additive manufacturing technologies, which includes selective laser melting (SLM) and electron beam melting, are used to manufacture prototypes and small series of metallic complex parts [2]. In the SLM process a wide range of materials is available for many applications and novel materials can be developed for specific applications [3]. SLM technique comprised many advantages such as complexshaped, light weighted and custom-made part manufacturing; nevertheless, some issues like hot cracks, residual stresses, porosities and lack-of-fusion defects can be present in SLM parts [4]. Lack of fusion defects occurred due to inadequate laser energy density. To prevent this defect, the energy concentration must be tuned by changing the manufacturing parameters [5]. The heating of the building platform is generally performed to decrease thermal stresses and reduce the formation of hot cracks within the material microstructure [6]. The relation between thermal gradient and residual stress was revealed by experimental methods and finite element analysis in ref. [7, 8].

Different thermal histories can lead to substantial differences in terms of microstructural and mechanical properties of the final component [9]. Estimating and controlling the microstructure of the processed material would be beneficial to achieve enhanced mechanical properties [10]. Many parameters such as laser speed, energy density, layer thickness and hatch distance affect the microstructure of materials during SLM process. Furthermore, some extra parameters that affect material microstructure should be considered, including orientation and position of components on the building platform and temperature distribution [11]. 
Ti6Al4V is widely used for additive manufacturing of components that are employed in medical and aerospace industries due to its lightness, biocompatibility and good compromised of mechanical properties [13]. Several studies regarding the effect of manufacturing parameters on Ti6Al4V microstructure were published $[14,15]$. Parameter optimization was accomplished to obtain small grains and homogenous microstructures [16]. Numerous studies addressed the investigation of microstructural defects such as cracks, and lack of fusion pores [17]. Grains of a'-phase and acicular martensite needles were found within the microstructure of T6AI4V produced by SLM [18]. As the cooling rate increases, the microstructure shows a higher quantity of martensite, leading to an embrittlement of the material [12]. In addition to that, some of the thermal situations could cause differences in the microstructures. In particular, higher grades of additional martensitic lines, dislocations, and twins emerged [19]. Prior researches have emphasized that twins which were restrained the elongation of martensitic lines and lead to precipitation of fine grains, lead to increased mechanical properties. Furthermore, secondary martensite lines affected the mechanical properties of materials as well. Some authors have driven the further development of the additive manufacturing of Ti6Al4V considering the effect of process temperatures and cooling rates on the final microstructure. The complexity of the microstructure consisted of a large martensitic lines, arising of secondary, ternary and quaternary martensitic lines, dislocations and twins $[20,21]$.

In this study, samples of Ti6AI4V were produced by SLM placed in different positions on the building platform in order to evaluate the effect of temperature distribution and cooling rate on the microstructure and porosity of the material. Moreover, the effect of different microstructure on the final hardness of samples was evaluated.

\section{Materials And Methods}

The chemical composition of the gas-atomized Ti6Al4V powder is reported in Table 1.

Table 1

Chemical composition of

Ti6Al4V

\begin{tabular}{|ll|}
\hline Material & \% by weight \\
\hline Titanium & 89.7 \\
\hline Aluminum & 5.9 \\
\hline Vanadium & 4.2 \\
\hline Iron & 0.1 \\
\hline Oxygen & 0.1 \\
\hline
\end{tabular}

A EOS M280 DMLS system was used to produce cubic samples using the gas-atomized Ti6Al4V powder. The majority of prior researchers have found that the optimum parameters were defined as $1250 \mathrm{~mm} / \mathrm{s}$ scanning speed, $170 \mathrm{~W}$ laser power, $0.7 \mathrm{~mm}$ hatching distance, $0.03 \mathrm{~mm}$ layer thickness, $67^{\circ}$ rotational 
scanning, and $50.7 \mathrm{~J} / \mathrm{mm}^{3}$ energy density [22]. Purity of argon gas was $99.999 \%$ to guarantee a controlled atmosphere during the process. The cubic samples were sized as $10 \times 10 \times 10 \mathrm{~mm}^{3}$. The distance between cubes was $5 \mathrm{~mm}$. The distribution of the samples on the building platform is depicted in Fig. 1. Besides, $2 \mathrm{~mm}$ block type support structures were implemented. Manufactured samples were cut from the build platform by wire electrical discharge machine.

The temperature distribution of the samples was inspected during manufacturing. The temperature of molten materials was found by the experimentally validated thermal camera measurements. Curves of temperature were achieved by Optris PI160 thermal camera system with $120 \mathrm{~Hz}$ frequency. The camera system was installed at the top surface of the manufacturing cabin to focus on the manufacturing platform. The camera recorded videos from $350 \mathrm{~mm}$ far away from the build platform at $14^{\circ}$. The emissivity value of Ti6Al4V material was experimentally defined between 0.31 and 0.38 depending on the temperature. The thermal image was focused on samples in order to compute the cooling rate experienced by the sample. The manufactured samples were cut to analyze two sections (top and middle, respectively) as reported in Fig. 1c. The relative density investigation and measurement of martensite lath width were carried out through image proccessing by using Image $\mathrm{J}$ software. Photos of 5 different areas on the surface of each sample were taken by optical microscope with 20x optical magnification. ImageJ software was used to investigate the relative density values. Microstructure analysis was carried out by Nikon Eclipse LV150NL light optical microscope (LOM) and by Zeiss Sigma 500 field emission scanning electron microscope (FE-SEM) equipped with Oxford Instruments Ultim Max detector for energy dispersive X-ray analysis (EDS). Leica Mod. VMHT 30 tester was used to evaluate the hardness of samples. A load of $100 \mathrm{~g}$ and a dwell time of 15 seconds were used to perform hardness tests. The hardness test was applied according to the ASTM E92-17 standard [23].

\section{Results And Discussions}

The temperature of the samples was recorded during the manufacturing process. The maximum temperature values of the top and middle sections of each sample are shown in Fig. 2. The maximum temperature value increases from the middle to the top section for every investigated sample, indicating that the material experiences a heat accumulation during the manufacturing process. The accumulation phenomenon was particularly evident on sample 3, probably due to its proximity to other samples and limited heat transfer condition (Fig. 1). Moreover, heat transfer mechanism, geometry and positioning of samples have a strong influence on the temperature gradients experienced by the material. [24, 25]. Temperature values obtained by the thermal camera were consistent with the literature [26].

The sections of samples parallel to the building platform were investigated by optical microscope in order to perform relative density analysis. The porosity values of samples are reported in Fig. 3 and range between $0.02 \%$ and $0.05 \%$. Mean Standard deviation of the results was found as $0.005 \%$. The middle section of the samples shows lower porosity values than those of the top section, probably due to the different thermal experience during the process. Indeed, higher maximum temperature values can 
promote the formation of a larger quantity of sputters, exhaust gasses and residues of burnt materials during the laser scan [27-30]. These phenomena can also cause increased porosity.

The section of as-built samples parallel to the building platform was etched by Kroll's reagent and investigated by optical and SEM microscopes. Surfaces of the samples were observed with 50x and 200x OM magnification, as reported in Fig. 4. The martensitic a' phase is noticeable within the microstructure of all investigated sections, in good agreement with literature results [31, 32].

SEM analyses were carried out on samples to observe the microstructure of the as-built material. Results are reported in Fig. 5. Martensitic laths with different thicknesses are visible within the microstructure of the as-built material. In particular, thin martensitic laths were recognized on the top surface of the samples (Fig. 5A-B), while thick martensitic laths were observed in the middle section (Fig. 5C-D). It was thought that the higher maximum temperature values achieved in the top section as seen (Fig. 2). This could lead to lower cooling rates due to lower temperature gradient, which was related to cooling through the melting temperature to mean layer temperature. Mean layer temperature increased during manufacturing from $35^{\circ} \mathrm{C}$ to $75^{\circ} \mathrm{C}$. Although this phenomenon was assumed to promote the formation of thicker martensitic needles due to the temperature gradient of the layer, microstructure was observed opposite. It was occurred owing to more effectual repetitive laser heating and cooling cycle in the middle section than the top section. Similar to this study, it was found that primary and secondary a' martensites were a little coarsening, while the finer ternary and quartic martensite laths were forming [21]. The High magnification SEM images are shown in Fig. 6 . Similar in the literature, twins were seen on the primary martensitic laths. Besides, primary, secondary and ternary a' martensitic laths were ascertained in the asbuilt microstructure. Thermal history induced severe internal stresses caused dislocations such as twins.

Figure 5. SEM images of Back sample, top surface (A), Center sample, top surface (B), Back sample, middle surface (C), Center sample, middle surface (D)

SEM images reported in Fig. 7 shows the evidence of white spots within the microstructure of the as-built material. These spots can be ascribed to the $\beta$ phase, probably related to agglomerations of vanadium atoms. Indeed, the $\beta$ phase can appear in form of white spots due to the higher vanadium content that results in a brighter contrast $[33,34]$.

Finally, the widths of primary martensitic laths were measured in order to understand the influence of the building position and maximum temperature of samples on the final microstructure. Results were reported in Fig. 8. The widths of martensitic lines were measured on 7 different laths with SEM images. Mean standard deviation of the measurements was calculated as $\pm 0.135 \mu \mathrm{m}$. Thinner martensitic laths are visible on top sections of both center and back samples. Besides, each sample had a different mean width of martensitic laths depending on the temperature distribution during the manufacturing process. The samples which are placed nearby the argon gas inlet were cooled faster according to temperature values of samples (Fig. 2). Thus the maximum temperature results observed higher far samples from the gas inlet. This phenomenon led to emerging thinner martensitic lines on neighboring fields to argon gas 
flow due to lower temperature gradient. Moreover, front areas of each sample had thicker martensitic lines than the back sides of the samples as seen in the Fig. 5 . While coarser primary martensite laths were formed, finer grains were existed due to forming secondary, tertiary and quartic martensite laths. Besides, in nearby areas such as edges and corners of two adjacent samples, secondary heat effects were noticed by analyzing the width of martensitic lines according to the observations in Fig. 5. In general, it is believed that the width of martensitic laths on sample 3 is larger than that of sample 5 due to heat concentration on the center of the building platform.

Micro hardness tests were performed both on top and middle sections of samples on center point, side edges and corners. Micro hardness values of the center point of samples are shown in Fig. 9, Fig. 10 and Fig. 11, respectively. Top section of the samples shows lower micro-hardness values than those of middle sections, probably due to the complexity (further a phase transformations) of the microstructures. Although the primary martensitic lath width of the top section was finer, additional martensitic lines (finer than the primary martensitic lath) on the middle section lead microstructure to more complex than the top section. Though the primary martensitic laths of the middle areas were larger than the top areas, middle areas were observed more complex than the top areas in the light of Figs. 5 and 6 . Significantly, lower hardness values were noticed on sample 3 than sample 5 due to coarser laths. Since the position of the back sample is closer to the gas inlet, higher cooling rate can be experienced by the material, leading to higher micro-hardness values. The hardness of the edges and the corners were similar. Even though the hardness values at the center of the samples were distinctly constant, however, the edges and the corners of the samples ought some scattered values of micro hardness, since the cooling rate of the side surfaces were higher than the center areas owing to heat transfers. Accordingly, the hardness on edges and corners were ranged between 365-400 HV and micro hardness values at the center points varied between 390-400 HV. The results were similar with previous studies wherein the hardness of the Ti6Al4V material in PBF additive manufacturing was measured between 330-400 HV [35].

Mean standard deviations of micro hardness values were found as $\pm 9.75 \mathrm{HV}$. According to previous results, the micro-hardness of samples fluctuates depending on the section and position of the samples on the building platform. Side surfaces, edges and corners were adequate owing to the resistance to friction, internal/residual stresses and deformations. Nevertheless, in case of the reaching excessive hardness, outer surfaces would be brittle. Therefore, unexpected failure mechanisms could be occurred.

\section{Conclusions}

In this study, the effects of positioning of samples on the manufacturing platform were investigated by various methods. Remarkable results were identified as seen below.

1. Some residues and exhaust gasses came in sight during the melting powders by the laser. Some additional constituents in the powders were burned and the residues which came up by the melting process were relocated to the sample 1 owing to the argon gas flow. Hence, the sample 1 was affected negatively and had a high porosity rate more than the others. 
2. Temperatures of all samples were linearly increased during manufacturing. The temperature gradient on the samples was not homogenous due to their positions on the building platform. Remarkably, the temperature on sample 3 , located at the center of the platform, had higher temperature values and lower temperature gradient than the others. Sample 3 had boundary conditions that made heat transfer difficult due to being surrounded by other samples.

3. The top section of samples showed thinner primary martensitic lines than the middle (inner) section but also the minimum primary martensitic line widths of the middle section were thinner than top section. The middle section of samples included secondary and ternary numerous sub-martensitic lines more than the top section. Furthermore, the center of the samples included thicker martensitic lines than side areas. As the laser melting the upper layers, previous layers were influenced. Further, heat performs like heat treatment upon the material. Upper layers of samples had fewer complex microstructures.

4. The most significant differences in temperature and hardness were noticed between the sample 3 and 5 since the higher cooling rate was observed on the back sample due to its closer position to gas flow hole. Higher cooling rates prompted to acquire harder samples because of martensitic transformation. Middle sections of samples had higher hardness values than the top section due to the complexity of $a^{\prime}$ phases and it was associated with multiple quenching of the material.

\section{Declarations}

Authors' contribution Mevlüt Yunus Kayacan was responsible for investigations, planning the experiments and writing the manuscript, Nihat Yılmaz carried out the review, the editing and project administration. All authors discussed the results, read and approved the final manuscript.

Funding Not applicable.

Availability of data and materials The authors confirm that the data supporting the findings of this study are available within the article.

Ethical approval Not applicable.

Consent to participate Not applicable.

Consent to publish The consent to submit this paper has been received from all co-authors. Competing interests The authors declare no competing interests.

\section{References}

1. Kayacan MC., Delikanli YE, Duman B, Ozsoy K (2018) Examining of mechanical properties of transitive (variable) porous specimens produced by SLS using ti6Al4v alloy powder. Journal of the Faculty of Engineering and Architecture of Gazi University, 33(1):127-143.

https://doi.org/10.17341/gazimmfd.406786

Page $7 / 21$ 
2. Badiru AB, Valencia VV, Liu D (2017) Additive manufacturing handbook: product development for the defense industry. CRC Press.

3. Poprawe R, Hinke C, Meiners W, Schrage J, Bremen S, Merkt S (2015) SLM production systems: recent developments in process development, machine concepts and component design. Advances in Production Technology, 49-65.

https://doi.org/10.1007/978-3-319-12304-2_5

4. Patterson AE, Messimer SL, Farrington PA (2017) Overhanging features and the SLM/DMLS residual stresses problem: Review and future research need. Technologies, 5(2):15. https://doi.org/10.3390/technologies5020015

5. Arısoy YM, Criales LE, Özel T, Lane B, Moylan S, Donmez A (2017) Influence of scan strategy and process parameters on microstructure and its optimization in additively manufactured nickel alloy 625 via laser powder bed fusion. The International Journal of Advanced Manufacturing Technology, 90(5-8):1393-1417.

https://doi.org/10.1007/s00170-016-9429-z

6. Zhao C, Fezzaa, K Cunningham RW, Wen H, De Carlo F, Chen L, Sun T (2017) Real-time monitoring of laser powder bed fusion process using high-speed X-ray imaging and diffraction. Scientific reports, $7(1): 1-11$.

https://doi.org/10.1038/s41598-017-03761-2

7. Ali H, Ma L, Ghadbeigi H, Mumtaz K (2017) In-situ residual stress reduction, martensitic decomposition and mechanical properties enhancement through high temperature powder bed preheating of Selective Laser Melted Ti6Al4V. Materials Science and Engineering: A, 695:211-220.

https://doi.org/10.1016/j.msea.2017.04.033

8. Li C, Liu ZY, Fang XY, Guo YB (2018) Residual stress in metal additive manufacturing. Procedia Cirp, 71:348-353.

https://doi.org/10.1016/j.procir.2018.05.039

9. Acharya R, Sharon JA, Staroselsky A (2017) Prediction of microstructure in laser powder bed fusion process. Acta Materialia, 124:360-371.

https://doi.org/10.1016/j.actamat.2016.11.018

10. Murr LE, Quinones SA, Gaytan SM, Lopez MI, Rodela A, Martinez EY, Wicker RB (2009) Microstructure and mechanical behavior of $\mathrm{Ti}-6 \mathrm{Al}-4 \mathrm{~V}$ produced by rapid-layer manufacturing, for biomedical applications. Journal of the mechanical behavior of biomedical materials,2(1):20-32. 
11. Song B, Dong S, Zhang B, Liao H, Coddet C (2012) Effects of processing parameters on microstructure and mechanical property of selective laser melted Ti6Al4V.Materials \& Design,35:120125.

https://doi.org/10.1016/j.matdes.2011.09.051

12. Scharowsky T, Juechter V, Singer RF, Körner C (2015) Influence of the scanning strategy on the microstructure and mechanical properties in selective electron beam melting of $\mathrm{Ti}-6 \mathrm{Al}-$ 4V. Advanced Engineering Materials, 17(11):1573-1578.

https://doi.org/10.1002/adem.201400542

13. Yadroitsev I, Krakhmalev P, Yadroitsava I, Du Plessis A (2018) Qualification of Ti6AI4V ELI alloy produced by laser powder bed fusion for biomedical applications. JOM, 7O(3):372-377.

https://doi.org/10.1007/s11837-017-2655-5

14. Yadroitsev I, Krakhmalev P, Yadroitsava (2014) I. Selective laser melting of Ti6Al4V alloy for biomedical applications: Temperature monitoring and microstructural evolution. Journal of Alloys and Compounds, 583:404-409.

https://doi.org/10.1016/j.jallcom.2013.08.183

15. Rafi HK, Karthik NV, Gong H, Starr TL, Stucker BE (2013) Microstructures and mechanical properties of Ti6Al4V parts fabricated by selective laser melting and electron beam melting. Journal of materials engineering and performance, 22(12):3872-3883.

https://doi.org/10.1007/s11665-013-0658-0

16. Shipley H, McDonnell D, Culleton M, Coull R, Lupoi R, O'Donnell G, (2018) Trimble, D. Optimisation of process parameters to address fundamental challenges during selective laser melting of Ti-6Al-4V: A review. International Journal of Machine Tools and Manufacture, 128:1-20.

https://doi.org/10.1016/j.ijmachtools.2018.01.003

17. Galarraga H, Lados DA, Dehoff RR, Kirka MM, Nandwana P (2016) Effects of the microstructure and porosity on properties of Ti-6Al-4V ELI alloy fabricated by electron beam melting (EBM). Additive Manufacturing, 10:47-57.

https://doi.org/10.1016/j.addma.2016.02.003

18. Yadroitsev I, Krakhmalev P, Yadroitsava I (2014) Selective laser melting of Ti6Al4V alloy for biomedical applications: Temperature monitoring and microstructural evolution. Journal of Alloys 
and Compounds, 583:404-409.

https://doi.org/10.1016/j.jallcom.2013.08.183

19. Vrancken B, Thijs L, Kruth JP, Van Humbeeck J (2012) Heat treatment of Ti6Al4V produced by Selective Laser Melting: Microstructure and mechanical properties. Journal of Alloys and Compounds, 541:177-185.

https://doi.org/10.1016/j.jallcom.2012.07.022

20. Cao S, Chen Z, Lim CVS, Yang K, Jia Q, Jarvis T, Wu X (2017) Defect, microstructure, and mechanical property of Ti-6Al-4V alloy fabricated by high-power selective laser melting. JOM, 69(12): 2684-2692.

https://doi.org/10.1007/s11837-017-2581-6

21. Yang J, Yu H, Yin J, Gao M, Wang Z, Zeng X (2016) Formation and control of martensite in Ti-6Al-4V alloy produced by selective laser melting. Materials \& Design, 10:308-318.

https://doi.org/10.1016/j.matdes.2016.06.117

22. Kayacan MC, Delikanlı YE, Duman B, Özsoy K (2018) Ti6Al4V toz alaşımı kullanılarak SLS ile üretilen geçişli (değişken) gözenekli numunelerin mekanik özelliklerinin incelenmesi. Gazi Üniversitesi Mühendislik-Mimarlık Fakültesi Dergisi, 33(1).

https://doi.org/10.17341/gazimmfd.406786

23. ASTM E92-17, Standard test methods.

24. Dunbar AJ, Denlinger ER, Gouge MF, Simpson TW, Michaleris P (2017) Comparisons of laser powder bed fusion additive manufacturing builds through experimental in situ distortion and temperature measurements. Additive Manufacturing, 15:57-65.

https://doi.org/10.1016/j.addma.2017.03.003

25. Criales LE, Özel, $T$ (2017) Temperature profile and melt depth in laser powder bed fusion of Ti-6Al-4V titanium alloy. Progress in Additive Manufacturing, Progress in Additive Manufacturing, 2(3):169177.

https://doi.org/10.1007/s40964-017-0029-8

26. Zhuang JR, Lee YT, Hsieh WH, Yang AS (2018) Determination of melt pool dimensions using DOEFEM and RSM with process window during SLM of Ti6Al4V powder. Optics \& Laser Technology, 103: 59-76.

https://doi.org/10.1016/j.optlastec.2018.01.013

Page $10 / 21$ 
27. Shutov, IV, Gordeev, GA, Kharanzhevskiy, EV, Krivilyov, MD (2017) Analysis of morphology and residual porosity in selective laser melting of Fe powders using single track experiments. In MD Krivilyov//IOP Conference Series: Materials Science and Engineering, 192.

https://doi:10.1088/1757-899X/192/1/012023

28. Ferrar B, Mullen L, Jones E, Stam, R, Sutcliffe CJ (2012) Gas flow effects on selective laser melting (SLM) manufacturing performance. Journal of Materials Processing Technology, 212(2):355-364.

https://doi.org/10.1016/j.jmatprotec.2011.09.020

29. Fousová M, Vojtěch D, Kubásek J, Jablonská E, Fojt J (2017) Promising characteristics of gradient porosity Ti-6Al-4V alloy prepared by SLM process. Journal of the mechanical behavior of biomedical materials, 69:368-376.

https://doi.org/10.1016/j.jmbbm.2017.01.043

30. Kasperovich G, Haubrich J, Gussone J, Requena G (2016) Correlation between porosity and processing parameters in TiAl6V4 produced by selective laser melting. Materials \& Design, 105:160170.

https://doi.org/10.1016/j.matdes.2016.05.070

31. Vrancken B, Thijs L, Kruth JP, Van Humbeeck J (2012) Heat treatment of Ti6Al4V produced by Selective Laser Melting: Microstructure and mechanical properties. Journal of Alloys and Compounds, 541:177-185.

https://doi.org/10.1016/j.matdes.2016.05.070

32. Thijs L, Verhaeghe F, Craeghs T, Van Humbeeck J, Kruth JP, (2010) A study of the microstructural evolution during selective laser melting of Ti-6Al-4V. Acta materialia, 58(9):3303-3312.

https://doi.org/10.1016/j.actamat.2010.02.004

33. Agius D, Kourousis KI, Wallbrink C, Song T (2017) Cyclic plasticity and microstructure of as-built SLM Ti-6Al-4V: The effect of build orientation. Materials Science and Engineering: A, 701:85-100.

https://doi.org/10.1016/j.msea.2017.06.069

34. Tao P, Li HX, Huang BY, Hu QD, Gong SL, Xu QY (2018) Tensile behavior of Ti-6Al-4V alloy fabricated by selective laser melting: Effects of microstructures and as-built surface quality. China Foundry, 15(4):243-252.

https://doi.org/10.1007/s41230-018-8064-8 
35. Khorasani A, Gibson I, Awan US, Ghaderi A (2019) The effect of SLM process parameters on density, hardness, tensile strength and surface quality of Ti-6Al-4V. Additive Manufacturing, 25:176-186.

https://doi.org/10.1016/j.addma.2018.09.002

\section{Figures}
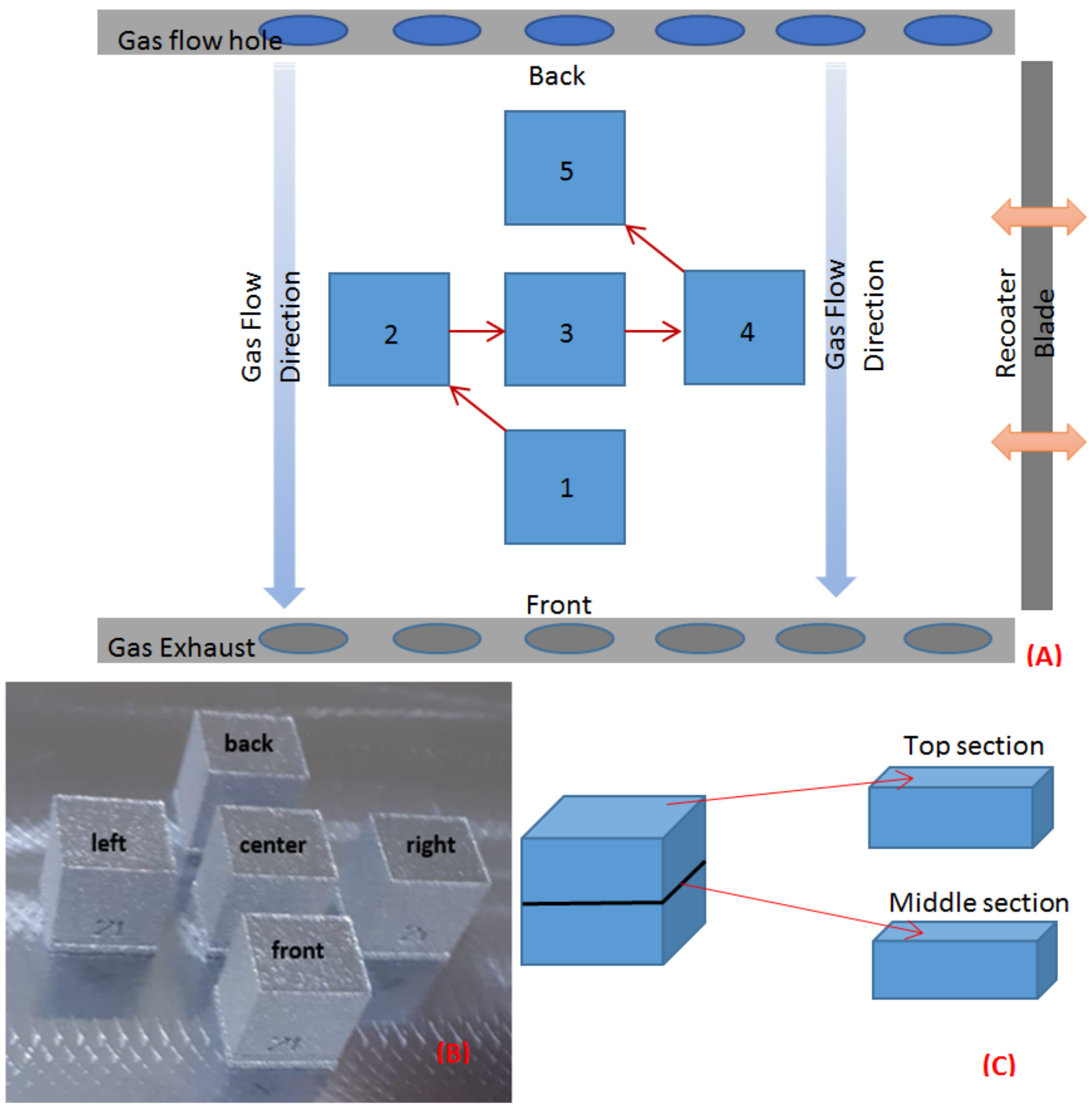

(c)

Figure 1 
A. Schematic of position of samples on building platform; B. Photo of manufactured samples; C. Schematic of analyzed sections

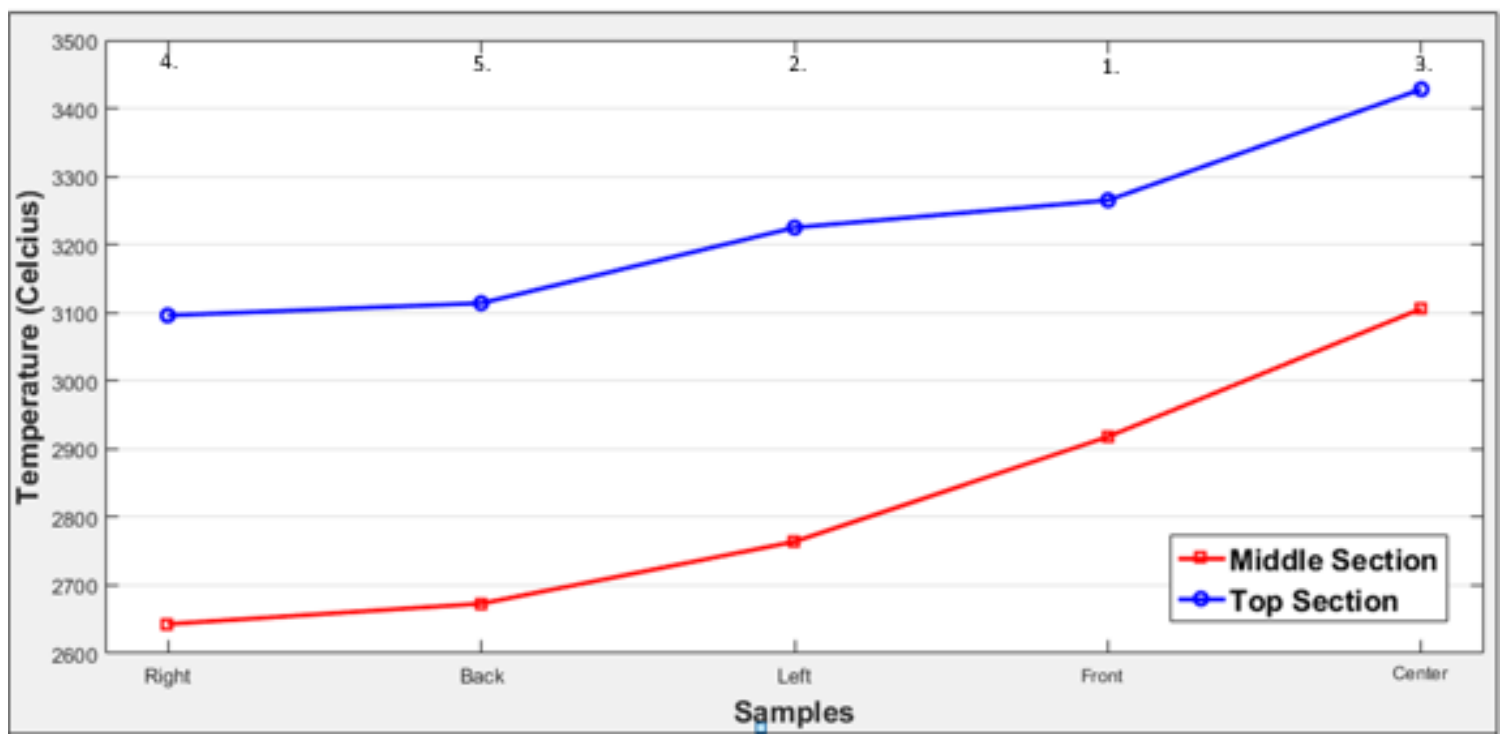

Figure 2

Peak temperatures on manufactured samples
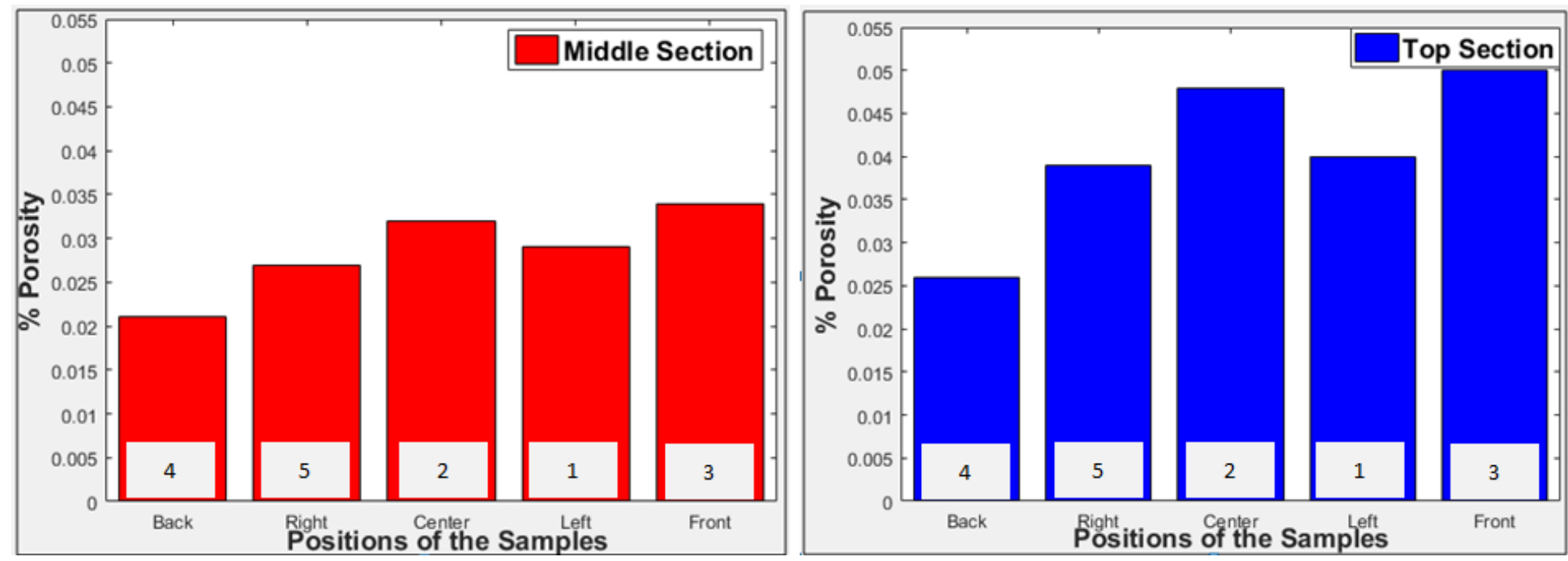

Figure 3

Porosity ratio of samples with regard to positions 


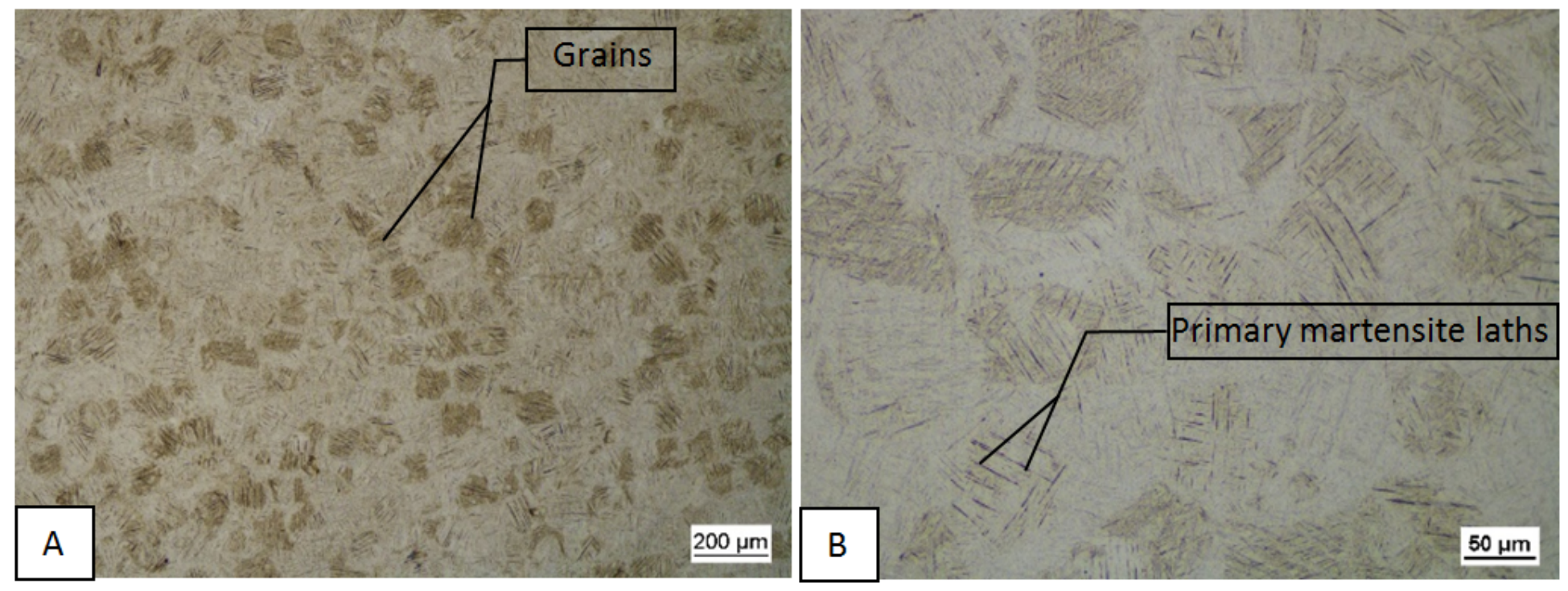

Figure 4

A) Low-magnification and B) high-magnification optical images of the section parallel to the building platform of as-built samples 


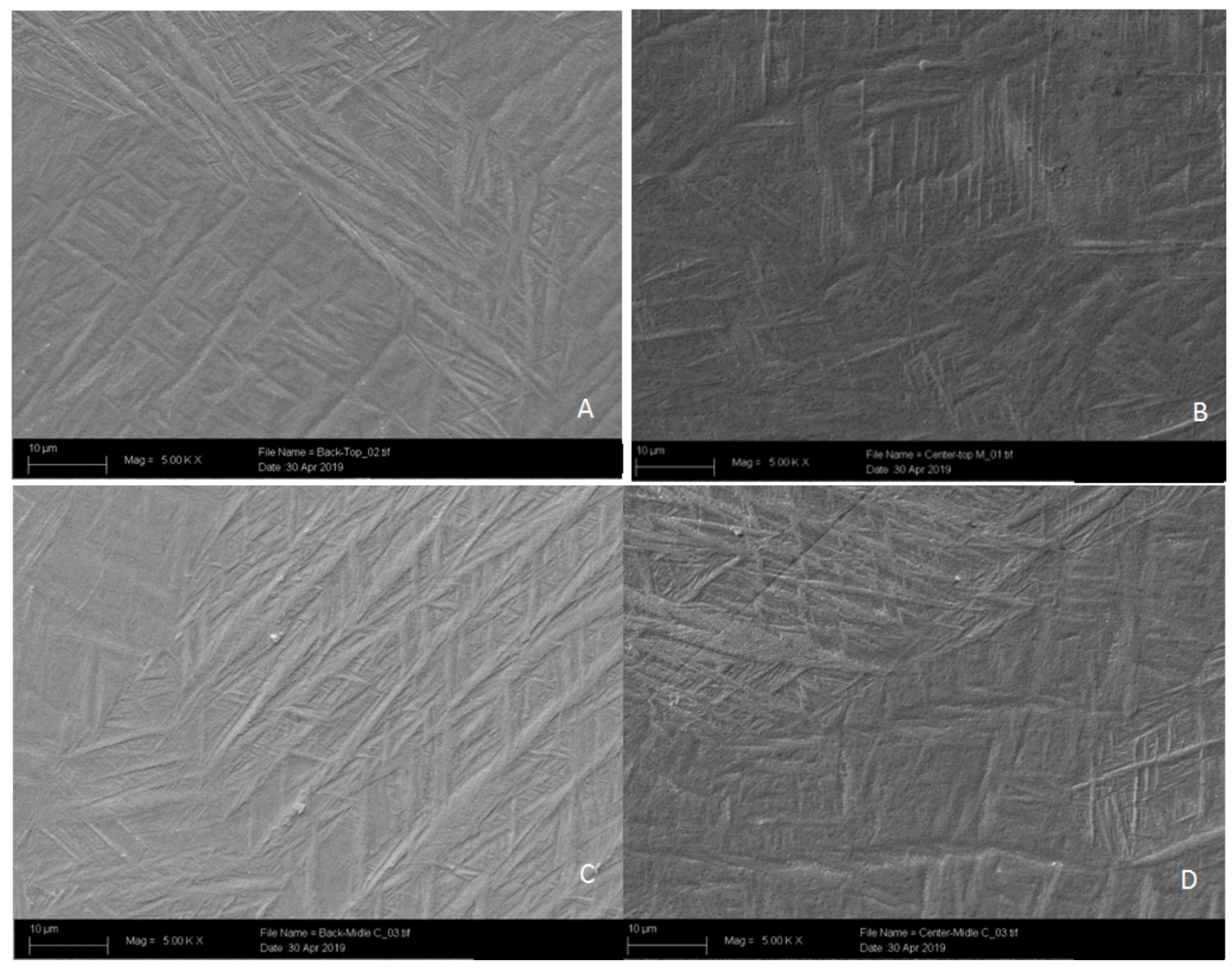

\section{Figure 5}

SEM images of Back sample, top surface (A), Center sample, top surface (B), Back sample, middle surface (C), Center sample, middle surface (D) 


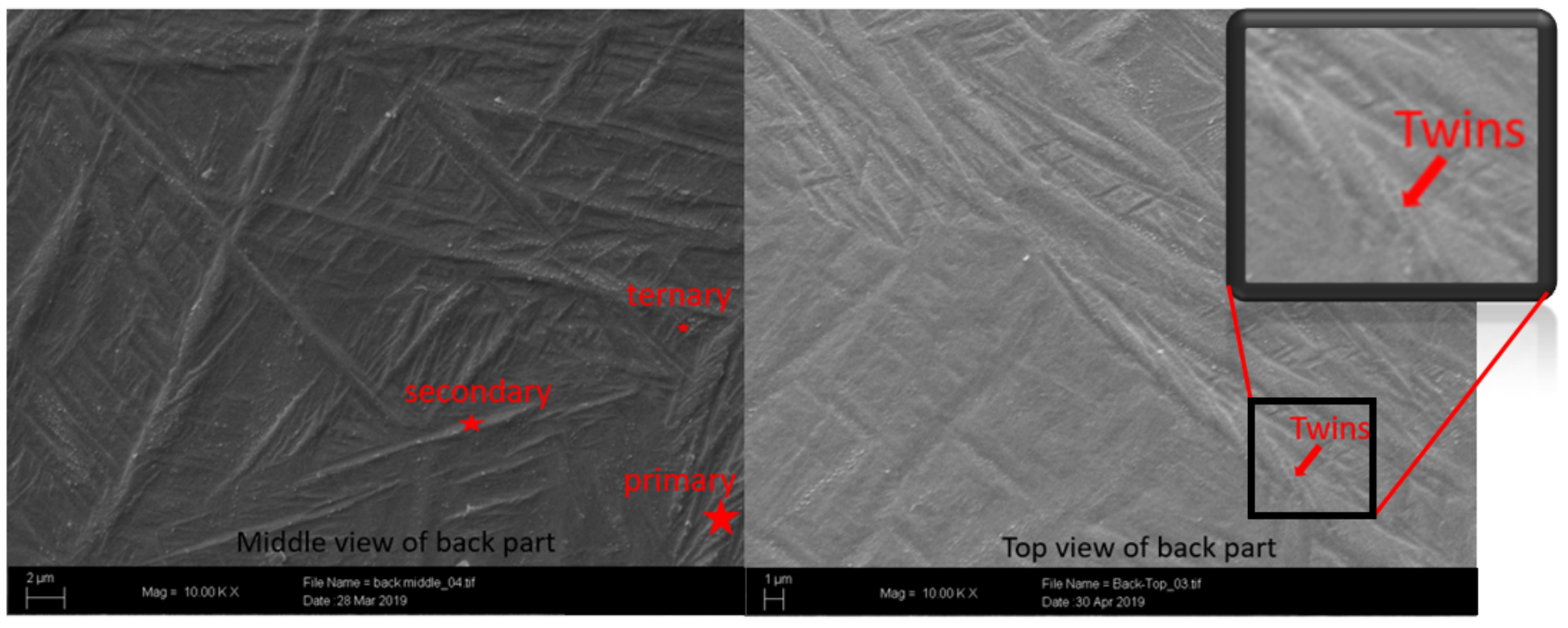

Figure 6

Twins and additional martensitic lines in a' phase 


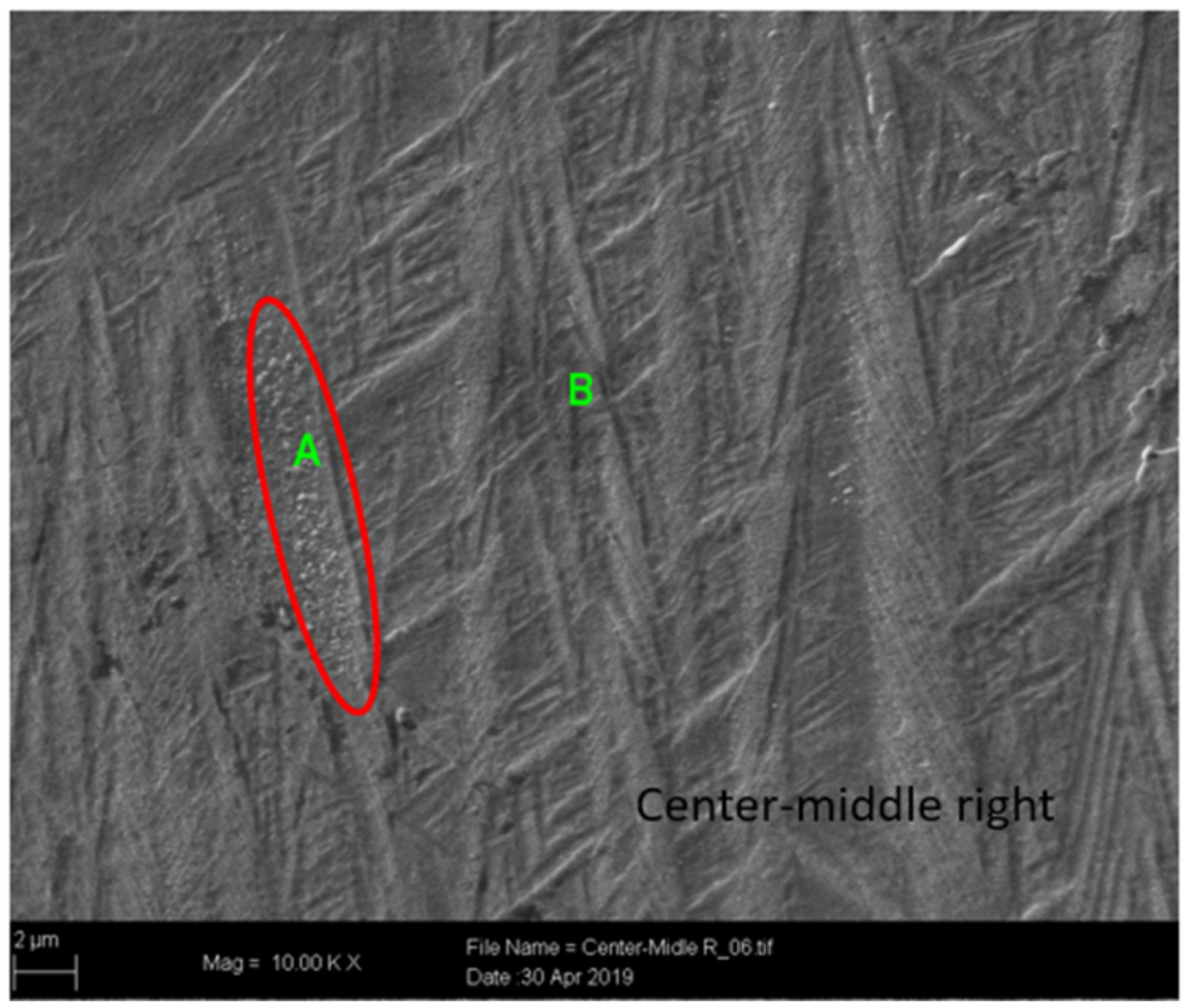

Figure 7

Agglomeration of $\beta$ precipitates in the $\alpha^{\prime}$ martensitic phase 


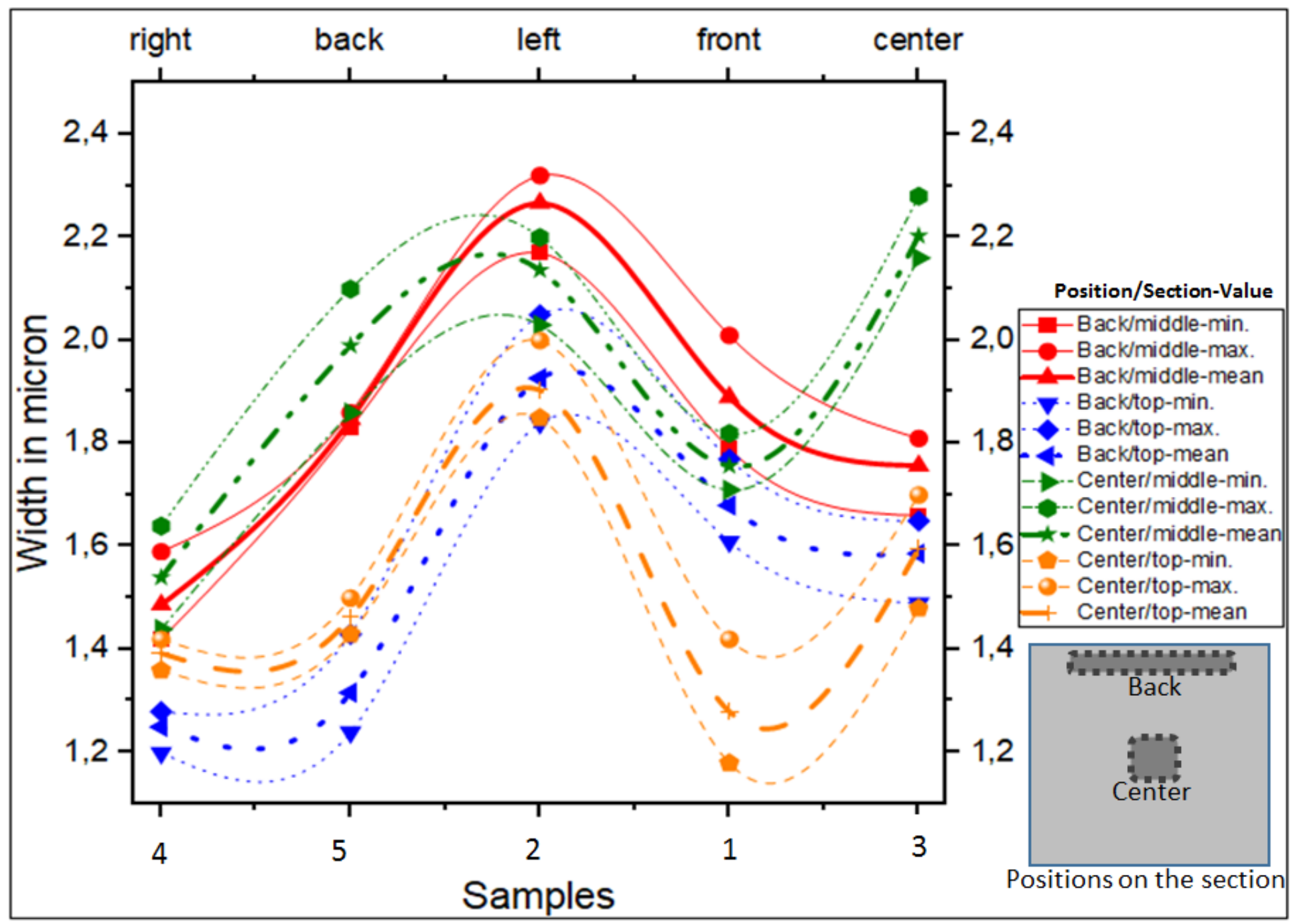

Figure 8

Primary martensitic lath width for different sections of samples 


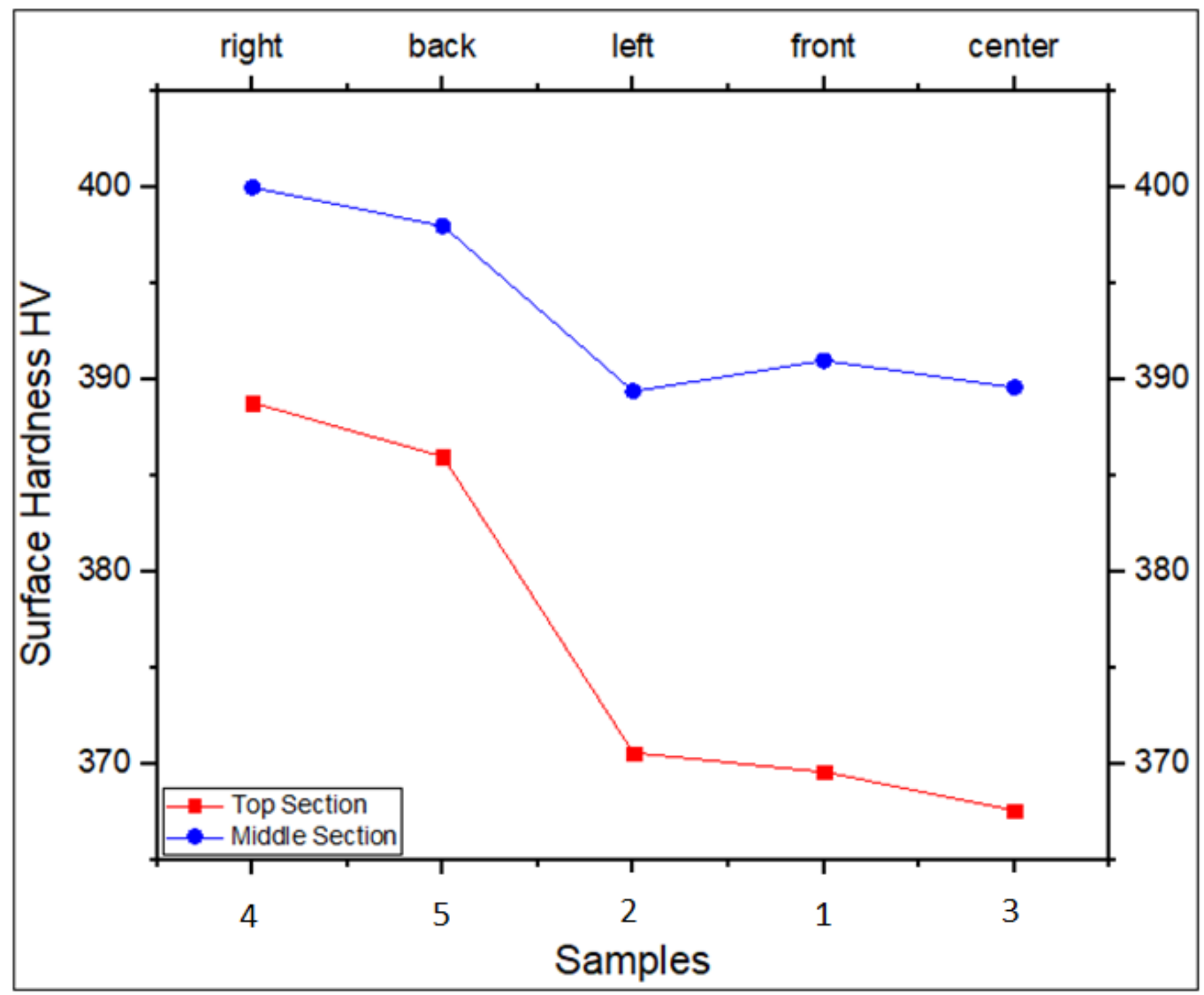

Figure 9

Micro hardness values of center point of samples 


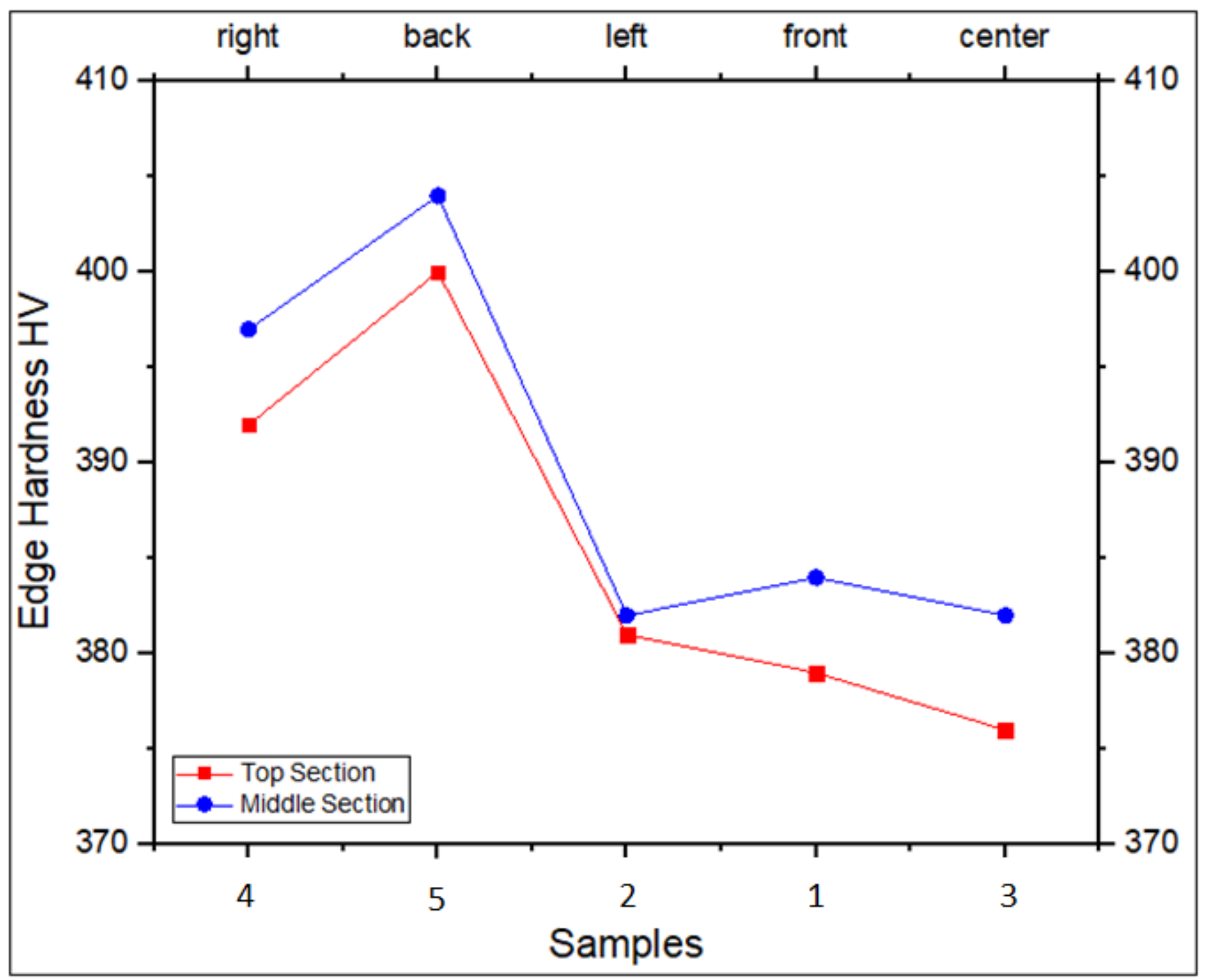

Figure 10

Micro hardness values of edge of samples 


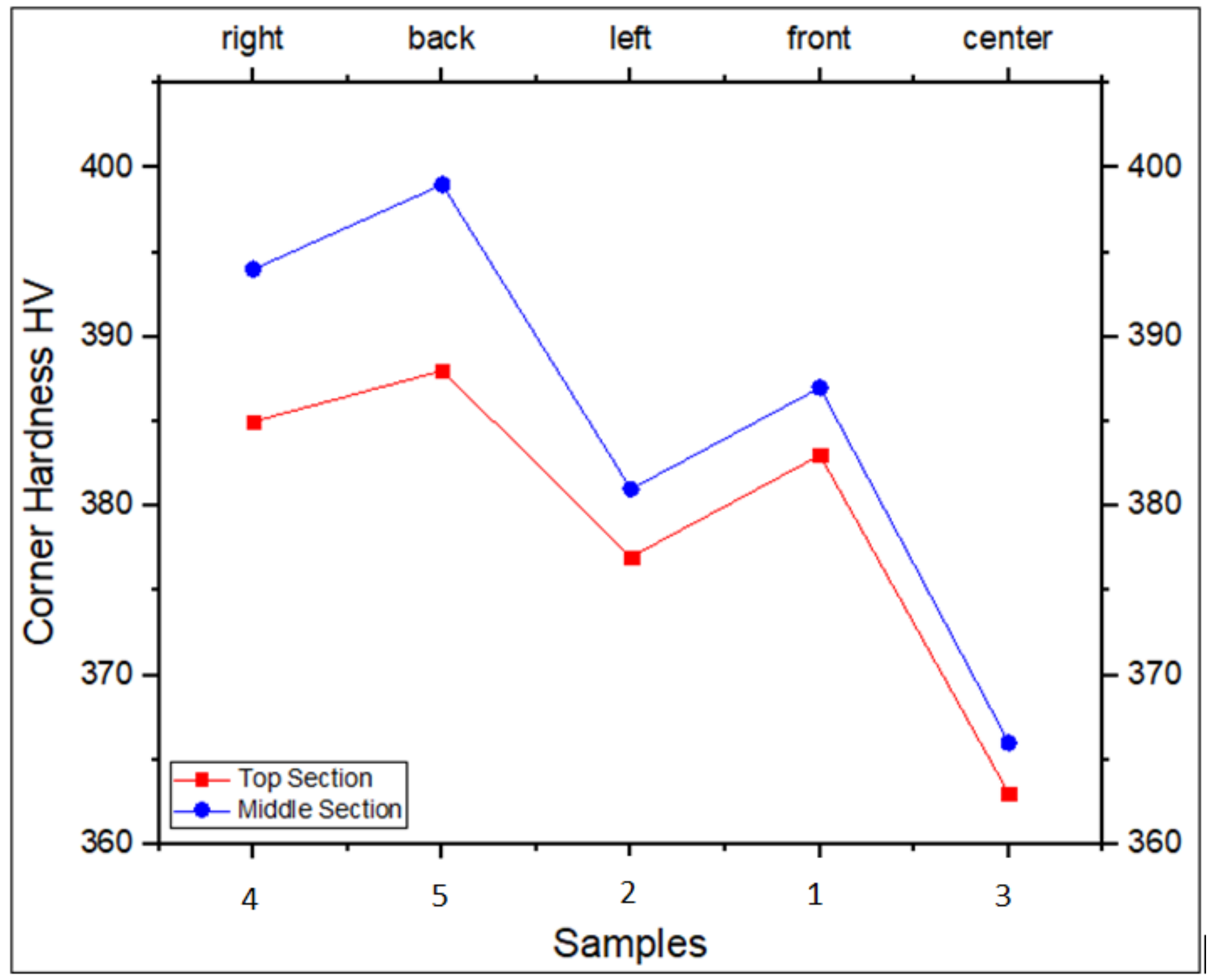

Figure 11

Micro hardness values of corner of samples

\section{Supplementary Files}

This is a list of supplementary files associated with this preprint. Click to download.

- table1.xIsx 